\title{
O horizonte não é linear: paisagem e espaço na Perspectiva Audiovisual Linear de Anton Corbijn
}

\author{
The horizon is not linear: landscape and space in the Anton \\ Corbijn Linear Audiovisual Perspective
}

\section{El horizonte no es lineal: paisaje y espacio en la Perspectiva Audiovisual Lineal de Anton Corbijn}

Cláudio Benito Oliveira Ferraz

Universidade Estadual Paulista - Campus de Presidente Prudente cbenito2@yahoo.com.br

Flaviana Gasparotti Nunes

Universidade Federal da Grande Dourados

flaviananunes@ufgd.edu.br

\begin{abstract}
Resumo
Neste texto pretendemos problematizar e refletir sobre alguns conceitos geográficos, especificamente espaço e paisagem, a partir de elementos e questões trazidas pela obra audiovisual intitulada Linear - um filme musical em que não há diálogos, apenas as músicas do álbum No Line on the Horizon da banda irlandesa U2 expressas por meio de imagens. Para esta reflexão tomaremos como referencial teórico as proposições de Gilles Deleuze e Felix Guattari que acreditamos serem de grande relevância para a Geografia na atualidade, principalmente no que se refere ao entendimento dos processos espaciais. Dos elementos da narrativa sonoro/imagética analisada a partir desses referenciais, concluímos que o espaço, qualificado como geográfico, não está a priori depositado nos lugares, ele é o acontecimento da mobilidade humana, que desterritorializa e reterritorializa novos sentidos e usos para os lugares, produzindo outras formas paisagísticas de percebê-lo e vivenciá-lo.
\end{abstract}

Palavras-chave: paisagem, espaço, som, imagem.

\begin{abstract}
In this text, the purpose is to discuss and reflect on some geographical categories and concepts, specifically space and landscape, based on the elements and issues brought about by the audiovisual work entitled Linear - a musical in which there is no
\end{abstract}


dialogue, only songs of the album, 'No Line on the Horizon', performed by the Irish band $\mathrm{U} 2$ which are expressed in images. In order to do this reflection, it was took as a theoretical referential the propositions outlined by Gilles Deleuze and Felix Guattarri, which - we believe - might be very relevant to Geography in the current period, specially as for the understanding of the spatial processes. After analyzing the elements of the sonorous/visual narrative based on the Deleuzian referential, it was concluded that the space - qualified as geographic - does not a priori reside in 'places'. Rather, it is the result of human mobility that (de)territorialize and (re)territorialize new meanings and uses for places, producing other forms of perceiving them and of living them.

Keywords: landscape, space, sound, image.

\begin{abstract}
Resumen
En este texto pretendemos problematizar y reflexionar sobre algunos conceptos geográficos, específicamente espacio y paisaje, a partir de elementos y cuestiones traídas por la obra audiovisual titulada Lineal - una película musical en la que no hay diálogos, tan solo las canciones del álbum No Line on the Horizon de la banda irlandesa U2 expresadas a través de imágenes. Para esta reflexión utilizaremos como marco teórico las proposiciones de Gilles Deleuze y Felix Guattari, las cuales creemos ser de gran relevancia para la Geografía en la actualidad, principalmente en lo que se refiere al entendimiento de los procesos espaciales. De los elementos de la narrativa audiovisual analizada a partir de esos referenciales, concluimos que el espacio, calificado como geográfico, no está en principio depositado en los lugares, él es el acontecimiento de la movilidad humana, que desterritorializa y reterritorializa nuevos sentidos y usos para los lugares, produciendo otras formas paisajísticas de percibirlo y vivirlo.
\end{abstract}

Palabras clave: paisaje, espacio, sonido, imagen.

\title{
Introdução
}

Neste texto pretendemos problematizar e refletir sobre alguns conceitos geográficos, especificamente paisagem e espaço, a partir de elementos e questões trazidas pela obra audiovisual intitulada Linear ${ }^{1}$. Sabemos que no interior da Geografia ocorre um debate quanto ao que vem a ser conceito para a organização do discurso científico, no entanto, como nosso referencial teórico se baseia nas ideias de Deleuze e Guattari (1992), entendemos que o campo ou plano de imanência filosófico é a instância criadora de conceitos, cabendo ao plano de referência científico estabelecer proposições, assim como o plano de composição artístico elaborar afectos e perceptos. A questão é como estabelecer intercessores de um campo, ou plano, com o outro, ou seja, fazer com que conceitos como o de espaço e paisagem afetem nossos perceptos permitindo elaborarmos proposições científicas que atualizem o estado de coisas com o qual melhor pensemos sobre o mundo a

\footnotetext{
${ }^{1} \mathrm{O}$ documento audiovisual Linear compôs uma das edições especiais do álbum No Line on the Horizon da banda U2. Direção de Anton Corbijn. 2009; Inglaterra/Austrália; 58 minutos.
} 
partir da linguagem geográfica. Nossa experiência aqui exercitará tal intento por meio da obra de Anton Corbjin.

Linear consiste numa experiência visual e sonora - segundo seu próprio diretor, Anton Corbijn². É um filme musical em que não há diálogos, apenas as músicas do álbum No Line on the Horizon da banda irlandesa U2 expressas em imagens. Não se trata de videoclipes, mas uma história narrada numa sequência de imagens agrupadas em torno de cada uma das músicas do referido álbum.

Para cada música, há um ambiente ou situação experimentada pelo personagem principal em sua jornada de retorno. Este, um possível migrante do norte da África trabalha como policial em Paris e, por algum motivo, precisa retornar ao seu país de origem. O personagem percorre de moto as estradas do sul da França, passando pela Espanha até chegar a Cádiz, onde pegará um barco a remo e atravessará o Mediterrâneo.

A história inicia-se mostrando a linha do horizonte de Paris e termina focando a linha do horizonte do Mediterrâneo; entre essas duas linhas planas e distantes, ocorre o mergulho do personagem nos percalços do viver.

No adentrar ao mundo a partir desses horizontes paisagísticos propostos pelo diretor, constatamos que as miríades de fragmentos imagéticos apontam para a não efetivação da linha de horizontes planos, retilíneos e harmoniosos, ou seja, que viver o mundo é um entrelaçamento de contingencialidades materializadas em paisagens a expressarem esses fragmentos imagéticos deformadores de qualquer idealização ética, estética ou teórica.

Para esta reflexão, tomaremos como referencial teórico as proposições de Deleuze e Guattari $(1992 ; 1995 ; 1997)$ que acreditamos serem de grande relevância para a Geografia na atualidade, principalmente no que se refere ao entendimento dos processos espaciais.

Inicialmente, apresentaremos algumas considerações sobre som e imagem no intuito de esclarecermos a partir de quais parâmetros estamos compreendendo a obra de Corbjin. Na sequência, passamos a discutir mais diretamente os elementos e situações da obra audiovisual em sua relação com

\footnotetext{
2 Anton Corbijn é um fotógrafo/cinegrafista holandês considerado cineasta devido a duas recentes produções (Control, 2007 e O americano, 2010). Sua trajetória é marcada por fotografar para capas de discos de importantes nomes da música como David Bowie, U2, Depeche Mode, entre outros e dirigir videoclipes, além de perfomances em shows como Devotional do Depeche Mode. A ligação fotografia/imagem e música para ele são intensas, o que sua própria trajetória pode revelar neste breve histórico.
} 
os sentidos geográficos por nós identificados, a luz dos referenciais de Deleuze e Guattari (1992; 1995; 1997).

\section{Som e imagem: esclarecimentos iniciais}

Carvalho (2007, p. 5), fazendo uso de Morais (1983), classifica os modos como ouvimos a música em três níveis que podem se interpenetrar:

1) O primeiro se dá no nível físico, corporal, aquele em que sentimos a materialidade do arranjo sonoro musical como um pulsar que nos leva a movimentar o corpo, como, por exemplo, “(...) um budista entrando em transe com os sons dos gongos e sinos. Ou um jovem que nesse estágio de escuta sente o impulso do ato de dançar em uma discoteca."

2) O segundo nível é ouvir emotivamente, em que a carga sonora adentra o nosso imaginário e estimula nossos sentimentos e emoções, potencializando sensações de dor, alegria, raiva, amor etc. “(...) É este modo de escuta que acabou sendo muito utilizado na sonoplastia tanto de cinema como de televisão para criar o chamado "clima ambiental"”.

3) Já no terceiro nível temos o ouvir intelectualmente, o qual ocorre quando passamos a entender a música como uma linguagem, com certa organização lógica dos seus elementos articuladores (timbre, tom, ritmo etc.). “(...) Ouvir música intelectualmente é perceber que música é constituída de estrutura e forma (...)".

Partindo dessa classificação, sonoramente insuficiente, mas articuladora para nossos objetivos neste texto, podemos deduzir que na interação música/imagem, tanto no cinema, quanto na televisão ou nos videoclipes, os produtores musicais focam os dois primeiros níveis de escuta, enquanto um grupo pequeno de especialistas exercita o terceiro nível.

No entanto, podemos fazer essa classificação derivar, dinamizando-a. Para qualquer música, como figura estética, nos afetar emocionalmente, tanto potencializando sentimentos prazerosos quanto sombrios ou de estranhamento, devemos estabelecer um contato físico com a mesma, sendo que, por mais que não entendamos a estrutura da linguagem musical, ela potencializa nosso imaginário para que possamos agenciar outros sentidos intelectuais interpretativos ou emotivos, outros planos de composição.

Nestes termos, ao assistirmos Linear, a experiência sonora/visual criada por Anton Corbijn, somos estimulados a, independente de não entendermos as letras das canções, nem a estrutura melódica e harmônica das músicas, tentar compreender o que as sequências de imagens querem dizer a 
partir daquela trilha sonora, mesmo que não conheçamos ou gostemos da banda $\mathrm{U} 2$.

Exercitamos nosso intelecto sobre as músicas e as imagens visando, a partir de experiências e imagens outras que já tivemos contato, projetarmos sobre o que estamos ouvindo/vendo para tirar outros sentidos imagéticos e sonoros. E quanto mais informações tivermos sobre a obra, mais sentidos poderão ser criados por nós.

Nesse aspecto, o apreciar uma obra toma outro caráter, muito mais rico e estimulante, não se reduzindo ao mero gostar fácil a partir daquilo que estamos acostumados a entender pelo "achismo" pautado no físico-sensório imediato, mas porque podemos criar também referenciais que auxiliem a melhor localizar a nós e a obra no mundo.

É neste sentido que entendemos a relevância dessa obra artística como potencializadora de sentidos e possibilidades reflexivas para o pensamento científico, em especial o geográfico, tendo em vista os elementos que permeiam a narrativa sonoro/imagética, conforme discutiremos a seguir.

\section{A paisagem não se reduz a um horizonte linear}

A partir deste momento, discutiremos a obra audiovisual Linear mais diretamente.

Primeira cena. Câmera parada mostrando uma grande panorâmica. A linha reta do horizonte divide a tela em duas partes. Na parte superior, o céu. $\mathrm{Na}$ inferior vemos uma cidade. A partir de nossas experiências imagéticas anteriores, identificamos alguns elementos da paisagem e deduzimos ser Paris. A partir dos indícios da referida cidade apresentados, projetamos outros referenciais que imobilizam nosso entendimento sobre Paris: sofisticação cultural, beleza arquitetônica, tradição de bom gosto etc.

Primeira desconstrução: cena seguinte, câmera subjetiva em movimento. Não vemos largos horizontes, apenas fragmentos de prédios e ruas. Junto com o personagem da narrativa fazemos um deslocamento rápido por dentro da paisagem parisiense. A partir do centro vamos caminhando para a periferia: são ruelas, setores comerciais populares, viadutos de concreto, pichações e sujeira. Uma nova cidade se forma em nosso imaginário, uma cidade como qualquer outra. Um lugar igual a toda grande cidade em suas diferencialidades territoriais.

Saltemos para a última cena. Câmera parada mostrando uma grande panorâmica. A linha reta do horizonte divide a tela em duas partes. Na parte superior, o céu. Na inferior vemos a vastidão do mar Mediterrâneo com um 
minúsculo barco a percorrê-lo. Após termos ouvido/visto a obra toda, projetamos outros sentidos para a ilusão de linearidade harmoniosa da paisagem ali apresentada.

Como no caso de Paris, não é a fisicidade da forma retilínea do Mediterrâneo visto de longe que engana nossos sentidos, pois esse na verdade é um espaço humano, demasiado humano. Como a cidade, a paisagem ali não se restringe a uma linha fixa no horizonte, mas se manifesta nas diferenças, constantemente dinâmicas, a acontecerem enquanto lugar, em cada fragmento de imagem vista, ouvida, percebida-vivida.

Neste contexto, podemos questionar: paisagem é, portanto, ilusão da forma da coisa que estamos vendo? Devemos buscar a essência da verdade num espaço por ela ocultado? Não. A paisagem é aquilo que projetamos de sentido no momento do encontro humano com o fenômeno. A paisagem não está só na forma superficial da coisa percebida, nem está apenas em nós, mas no momento do encontro físico-sensorial, intelectual e imagético.

Paisagem é a superfície, a mais profunda superfície, daí, ser necessário ler a profundidade de sua superfície não só com os olhos, mas com o conjunto de sensações humanas, ampliando nossos referenciais de entendimento e percepção.

Nesse aspecto, a obra de Corbjin estabelece outra desconstrução de nossos referenciais de entendimento. $\mathrm{O}$ mar não é um horizonte linearmente plano e harmonioso; é, na verdade, miríades de corpos e forças em movimento, virtualidades potencializadoras de devires contingenciais ${ }^{3}$ a formarem ondas irregulares. Podemos não ver a desova de um cardume, nem o vazamento de óleo de um petroleiro, nem uma chuva ácida caindo no litoral turco, nem todos os ventos a moverem as águas, nem as diferentes densidades das correntes marinhas, mas vemos o agenciamento de tudo isso na forma dos movimentos irregulares das ondas que ameaçam virar o barco. Todos esses elementos e fenômenos são agenciados para que o devir onda ali aconteça no encontro com o deslocar humano.

Temos, assim, virtualidades que permitem o devir acontecer de forma não precisa nos diferentes lugares a partir do momento em que ocorre o encontro com o deslocar humano. É na paisagem que a virtualidade do não percebido se atualiza como acontecimento do devir de tudo que o forma, como

\footnotetext{
${ }^{3}$ Conceitos elaborados por Deleuze, em intrínseco trabalho com Guattari, que fundamentam o sentido mais geográfico do que histórico do pensamento filosófico. Segundo esses próprios autores, o virtual não se antepõe ao real, mas é a potência do mesmo se atualizar, assim como o devir não é resultado de uma linearidade temporal em que o passado explica o presente e define o futuro, mas é a própria duração temporal na contingencialidade das coisas acontecerem espacialmente. Para mais detalhes, ver Deleuze e Guattari (1992).
} 
um agenciamento maquínico de corpos e coletivo de enunciados. É na paisagem que as formas das coisas nos afetam e instigam nossos perceptos a pensarem sobre como essas se apresentam no território, estabelecendo determinada regionalidade e processo. Para tal, agenciamos nossos referenciais elaborados coletivamente, tanto os presentes nos mecanismos e corpos articulados em dada coletividade, quanto os produzidos por meio das diversas linguagens e enunciados viabilizadores dos processos com os quais podemos localizar e nos orientar perante o mundo, conforme apontam Deleuze e Guattari (1992; 1997). Saber perceber essas potencialidades a partir da profundidade da superfície é um dos desafios para o pensamento geográfico.

Tanto a cidade quanto o mar são um todo espacial cuja forma superficial é expressão de tudo que os produz. Isso não significa dizer que a paisagem urbana ou mediterrânea esconda algo, como se o fenômeno em si possuísse uma paisagem a encobrir um espaço oculto.

O problema é que temos dificuldade em pensar sobre o fenômeno de maneira diferente disso, pois nos limitamos a crer na paisagem apenas como horizonte que se projeta do fenômeno para o nosso olhar, ao invés de entendêla como uma superfície em que o encontro ocorre, potencializando o agenciamento de corpos, forças e pensamentos a partir de nossos desejos, necessidades e objetivos.

Tais referenciais de entendimento nos instrumentalizam para pensar sobre o fenômeno da mobilidade na produção contingencial do espaço a partir da obra analisada. É o que faremos no próximo item.

\section{Espaço como mobilidade humana}

Quando o personagem se desloca, projetamos o sentido de mobilidade do mesmo a partir de nossa referência hegemônica de movimento no espaço. Geralmente, entendemos o movimento como o deslocamento de um corpo de um ponto A para um ponto B, como se a distância percorrida fosse algo em separado do corpo e da própria mobilidade em si. Um palco em que algo se desloca por cima, não havendo interferências qualitativas entre os elementos que participam desse processo. No entanto, Deleuze (2009, p. 22-23) aponta outra forma de entender essa relação:

O movimento é uma translação no espaço. Ora, de cada vez que há translação de partes no espaço há também mudança qualitativa num todo [...]. [...] Se considero abstratamente partes ou lugares, $\mathrm{A}$ e $\mathrm{B}$, não compreendo o movimento que vai de um ao outro. Mas estou em A, tenho fome, e em B há comida. Quando atingi B e comi, o que mudou não foi só o meu estado, foi o estado do 
todo que compreendia $\mathrm{B}, \mathrm{A}$ e tudo o que havia entre os dois [...]. [...] O nosso erro é julgar que o que se move são elementos quaisquer exteriores às qualidades. Mas as próprias qualidades são puras vibrações que mudam ao mesmo tempo que se movem os pretensos elementos.

Esta ideia de Deleuze propicia outra desconstrução de nossos referenciais de entendimento. Ao assistirmos a obra em questão, enquanto geógrafos, tendemos a entender a geograficidade presente na mesma a partir das linhas de horizontes paisagísticos que expressam territórios físicos estanques sobre os quais o personagem se desloca.

Primeiro Paris, depois o interior rural da França, após a travessia dos Pireneus chega a Cádiz e termina no horizonte paisagístico do mar Mediterrâneo. Cada um desses trechos do trajeto é entendido como a base geográfica por ele percorrida: de $\mathrm{A}$ para $\mathrm{B}$, depois para $\mathrm{C}$, daí para $\mathrm{D}$ etc. A base física se coloca como independente do que o personagem faz, almeja, tem necessidade e assim por diante.

Com base no entendimento de Deleuze explicitado na citação anteriormente destacada, podemos agenciar outros sentidos, já que o ato de deslocar significa uma translação espacial, interferindo nos referenciais de todos os envolvidos, pois o deslocar no território muda o sentido espacial dos lugares para quem o percorre e para quem/o que com ele entra em contato.

Atravessar os Pirineus, ou o mar Mediterrâneo, para quem sai de férias é diferente do que para alguém que está a trabalho, muito diferente do que para quem está migrando, e bem diferente para nós que assistimos a obra de Corbijn e vemos uma migração ao contrário, de retorno para a África. Nesse aspecto, a solidez das montanhas ou a uniformidade das águas mediterrâneas são ilusões, pois, na verdade, esses lugares mudam sua paisagem conforme os objetivos, necessidades, interesses ou dúvidas daqueles que se movem por entre suas formas. Acreditamos ser isso que Deleuze quer dizer quando se refere ao espaço mudar conforme mudam os elementos.

Nesse ponto, para nossa perspectiva, reside o sentido geográfico mais instigante apresentado em Linear. A geografia não está em separado do movimento humano, como se fosse algo que o homem fizesse sobre; a geografia é o próprio acontecer dessa mobilidade que potencializa novos sentidos e leituras dos lugares.

O espaço, qualificado como geográfico, não está a priori depositado nos lugares, ele é o acontecimento da mobilidade humana, que desterritorializa e reterritorializa novos sentidos e usos para os lugares, produzindo outras formas de percebê-lo e vivenciá-lo. O emprego dos termos desterritorializar e 
reterritorializar a partir da leitura de Deleuze e Guattari (1992) não se restringe ao aspecto físico do território e da mobilidade que ocorre sobre o mesmo. São conceitos que articulam a compreensão do processo de produção do pensamento, portanto, de como as coisas acontecem no mundo enquanto encontro dos fenômenos com o pensar. Território, neste caso, não é algo que se torna fixo, passível de cristalizar uma forma de poder em si, mas é constante processo em que as forças que buscam o equilíbrio e a conservação num dado lugar acabam se tensionando com outras que contingencialmente acontecem, desconstruindo a solidez aparente e instaurando as potências virtuais do devir outro.

O espaço geográfico não está a priori no fenômeno urbano de Paris, nem no fenômeno geomorfológico das formações rochosas do Pirineus, muito menos nas vastas extensões dos mares e oceanos.

O geográfico se dá no momento do encontro em que o deslocar humano vai produzindo sentidos para os fenômenos, transformando os mesmos conforme os usos e necessidades humanas. Nesse encontro, a paisagem toma sentido espacial, se territorializa com determinada regionalização, fazendo da relação dos lugares uma mobilidade conforme o ser humano se desloca, se movimenta.

A África não está ali parada e nem a Europa está estanque, como se o personagem apenas se deslocasse sobre estas; ambos os lugares se tensionam e se deslocam no próprio movimento do personagem, que agencia outros sentidos paisagísticos, estabelecendo linhas de fuga ${ }^{4}$ de referenciais de entendimento fixos e generalizantes, territorializando outros sentidos e vivências espaciais, nos quais as dúvidas, desejos, temores e objetivos, expressos nos olhares e ações do personagem, acontecem.

\section{A sonoridade produz sentidos humanos para o lugar: o ritornelo U2}

A fim de verticalizarmos os argumentos e ideias até agora expostos, iremos abordar, de forma mais direta, a questão da música na obra Linear. Nossa intenção não é descrever cada uma das canções e interpretar suas letras, mas focar o sentido da música na direção do que delineamos como geográfico a partir dos referenciais deleuzianos.

\footnotetext{
${ }^{4}$ Linhas de fuga é um conceito central do pensamento de Deleuze e Guattari, pois é a própria força do devir outro acontecer, instigando rizomaticamente novas potências instauradoras de outras possibilidades frente aos valores até então consolidados, aos poderes e ordem estabelecidos. Linha de fuga não é fugir em si, mas instaurar o até então não pensável ou praticável. Mais detalhes, ver Deleuze e Guattari (1995).
} 
Somos muito dependentes do sentido da visão. Daí insistirmos numa concepção de geografia a partir da fisicidade estanque da paisagem vista em cada lugar. Se entendermos a geografia como mobilidade humana a acontecer espacialmente, transformando os sentidos e vivências espaciais, muitos apresentarão restrições a essa inconstância, acreditando que dessa forma não conseguiremos o rigor necessário para produzir conhecimento científico.

Apesar disso, acreditamos que se sairmos do estritamente visual e agenciarmos outros sentidos perceptivos, poderemos perceber o território como algo extremamente móbil e não restrito a uma suposta constância de sua base física. É o caso do território enquanto lugar de identidade demarcada pela sonoridade.

Voltemos a nosso objeto de análise - o audiovisual Linear, no qual vários lugares nos são visualmente apresentados - para explicitarmos melhor o que pontuamos no parágrafo anterior. Olhamos a África e a generalizamos como um lugar fixo, linearmente coeso em sua formação. A partir desse ponto de vista, todo aquele que ali nasce será um africano, com todos os valores culturais de um africano, com as savanas, o Saara, florestas equatoriais, camelos, elefantes e demais referenciais estereotipados que entendemos como próprios da identidade africana. $\mathrm{O}$ mesmo podemos fazer em relação à França. Um lugar fixo em sua linearidade de formação, com todos os elementos generalizantes definidores de uma identidade francesa.

No entanto, ao ouvirmos Linear e interagirmos com o que vemos, a música tensiona-se com o que cremos ver. A identidade não permanece linearmente fixa no horizonte imagético que temos dos lugares. As canções falam de redenção dos erros, de assumir quem você é, que não há linhas no horizonte, sobre a duração temporal e a inconstância espacial nos cedros do Líbano, sobre quem somos nós se não existem mais referenciais amplos padronizadores de identidades.

As músicas passam de ternas baladas a sujas batidas de blues, alternando solos de guitarra, gritos do vocalista e emotivos cantos em coral. Fragmentam-se as linearidades supostamente vistas nas imagens paisagísticas apresentadas na tela.

Nesse ponto, colocam-se outros questionamentos: quem é esse personagem mudo na história ali narrada? Será um mulçumano? Então, por que tantas referências à religiosidade cristã? Será um migrante árabe ou um mestiço ocidentalizado? Qual a causa de sua migração clandestina para o norte da África? Tantas perguntas que nos desorientam ainda mais porque não há respostas. No entanto, os vários fragmentos imagéticos e sonoros pontuam pistas. 
Inicialmente, percebemos que foram intercaladas cenas e músicas voltadas para as amplas paisagens com aquelas que focam os detalhes de pequenos ambientes. Nas primeiras, o homem mergulha no mundo e se despersonaliza; nas segundas, ele tenta estabelecer um centro de referência a partir dos elementos próximos. Abordemos um exemplo.

Após a tomada aérea em movimento focando a moto em meio à grandiosidade dos Pirineus, temos a cena fechada na intimidade sufocante do restaurante. Enquanto o personagem se alimenta no ambiente vazio e frio, o silêncio e melancolia se materializam nos olhares que tanto ele quanto a garçonete projetam. A necessidade de conferir um sentido mais vital àquele lugar leva a garçonete a ligar a televisão. Surge a banda U2 interpretando a música Magnificent, mas a imagem é distorcida na TV, suja, sem foco, cheia de fantasmas. Só a música preenche o ambiente. Os olhares são vazios, mas a sonoridade potencializa novos sentidos humanos para o lugar. A música toca a sensibilidade dos presentes, desdobrando-se em sentidos vários na busca individual por um lugar, por um sentido de identidade em meio ao caos do mundo que os cerca.

Essa situação nos lembra das palavras de Deleuze e Guattari (1997, p. 116) quando dizem: “(...) Uma dona de casa cantarola, ou liga o rádio, ao mesmo tempo em que erige as forças anti-caos de seus afazeres. Os aparelhos de rádio e tevê são como um muro sonoro para cada lar e marcam territórios $(\ldots)$ "

O mundo, a partir de uma visão generalizante, aparenta uma linearidade harmoniosa. Na verdade, como os labirintos de ruelas escuras na cidade de Paris, ou as ondas irregulares do Mediterrâneo, ele é puro caos.

A necessidade de estabelecer certo sentido para o mesmo é que força os seres humanos elaborarem referenciais de conhecimento a partir do lugar em que se encontram. Enquanto imagem em si, o que captamos do mundo são como aquelas distorções projetadas na tela da televisão, mas a sonoridade funciona como uma espécie de delimitação de um território que permite aos homens se identificarem com a forma de sua organização, terem segurança em percorrê-lo.

Sendo assim, o som desterritorializa essa visão da linearidade das formas; esse horizonte linear repercute nos detalhes dos ambientes como espaços de opressão, de vazio, de falta de sentido humano.

O som estabelece linhas de fuga frente a essa forma de perceber/viver o mundo como uniformidade, territorializando novas potências, novos devires de sentidos para os lugares. Por isso, a dona de casa canta, por isso ligamos o rádio e a televisão, para buscar uma certa identidade com o lugar, para que o 
lugar passe a acontecer como pertencimento e intimidade territorial. Neste caso, temos o sentido mais geográfico do conceito de ritornelo:

I. Uma criança no escuro, tomada de medo, tranqüiliza-se cantarolando [...]. Esta é como o esboço de um centro estável e calmo, estabilizador e calmante, no seio do caos. [...]

II. Agora, ao contrário, estamos em casa. Mas o em-casa não preexiste: foi preciso traçar um círculo em torno do centro frágil e incerto, organizar um espaço limitado [...]. Eis que as forças do caos são mantidas no exterior tanto quanto possível, e o espaço interior protege as forças germinativas de uma tarefa a ser cumprida, de uma obra a ser feita. [...]

III. Agora, enfim, entreabrimos o círculo, nós o abrimos, deixamos alguém entrar, chamamos alguém, ou então nós mesmos vamos para fora, nos lançamos [...]. Lançamo-nos, arriscamos uma improvisação. Mas improvisar é ir ao encontro do Mundo, ou confundir-se com ele. Saímos de casa no fio de uma cançãozinha. Nas linhas motoras, gestuais, sonoras que marcam o percurso [...] (DELEUZE; GUATTARI, 1997, p. 116117).

Aqui temos o ritornelo: as três características explicitadas na citação de Deleuze e Guattari acima transcrita não expressam etapas sucessivas, mas um processo em que esses aspectos se intercalam. É sempre um movimento em que o encontro com um fenômeno novo leva a buscar um sentido para o mesmo no lugar do encontro.

A partir disso, o delimitamos territorialmente, o regionalizamos, localizamos e orientamos o mesmo em relação a nós, fazemo-nos sentir emcasa conforme as palavras dos autores. No entanto, essa casa não preexiste, ela acontece territorialmente ao definirmos o sentido do fenômeno. Aquilo que não compreendemos fica além fronteira dessa regionalização.

Mas a fronteira permite o contato com que está além, assim como a inerência da mobilidade permite o que está do lado de fora entrar e o que está do lado de dentro sair, desterritorializando-se, estabelecendo novas linhas de fuga, para mais uma vez tentar ordenar o desconhecido, como uma criança que canta para seus temores se afastarem do lugar em que se localiza.

O ritornelo é como o canto dos pássaros, que demarcam o seu território em relação aos outros. Mas, como todo canto é um som, demarcar um território sonoramente é bem diferente de demarcá-lo por aspectos visuais.

A visão tende a linearizar os horizontes, fazendo do território uma generalização paisagística uniforme cujas diferenças dos detalhes não podem ser percebidas a distância (como as ruelas de Paris ou as ondas do mar, por 
exemplo). Quando se adentra a paisagem, a visão não consegue perceber as distâncias, fica reduzida ao imediatamente próximo perceptível - quem está no meio de uma floresta tem a visão da mesma circunscrita à barreira de árvores ao redor.

Mas o som tem um deslocamento físico no território, ele percorre as distâncias paisagísticas reverberando por entre suas irregularidades, produzindo ecos e distorções, não se lineariza; ele faz com que a forma de determinado lugar, sua paisagem, aconteça numa dada territorialização em conformidade a contingência com que encontra suas irregularidades.

No meio de uma floresta, o canto de um pássaro perpassa a barreira de árvores, vai além, logicamente que se modifica ao assim fazer. Essa percepção transformada da coisa em si é que faz do encontro o momento em que o espaço acontece em conformidade com as relações por nós estabelecidas, não mais se restringindo a um a priori, um em-casa preexistente, mas enquanto fenômeno que se constitui na relação.

Nesse momento, contingencialmente nos localizamos e tomamos consciência do que queremos e do que podemos fazer e para onde almejamos ir, ou seja, nos orientamos no lugar como processo de construção de nós mesmos no/com mundo, não como resultado de um conhecimento puro e linear, mas como processo prenhe de recriações e contingências.

\section{Considerações Finais}

Diante do exposto, com base nos referenciais de Deleuze e Guattarri (1992; 1995; 1997), podemos entender que o personagem da narrativa sonoro/imagética Linear busca justamente saber quem ele é, quer se localizar no mundo, saber se orientar, deseja construir sua própria espacialidade como forma do mundo acontecer em seu devir tempo-espacial.

O deslocar por entre as amplas paisagens vistas não permite ao mesmo sentir-se pertencente ao seu território. A sonoridade da música, com todas as suas diferenças, aponta para a busca do seu acontecer em-casa, delimitando o seu território, a sua geografia.

No entanto, o sentido do em-casa não está a priori dado, como algo fixo, uniforme e fechado, é algo que a sonoridade potencializa como devir de novos sentidos espaciais. Neste aspecto, podemos dizer que a música do U2 é o ritornelo sonoro frente à linearidade visual.

As imagens sonoramente tensionadas delimitam o sentido de mundo de forma dinâmica, não mais estabelecendo uma fronteira fixa em que o outro, o do lado de fora ali não entre, ou nós do lado de cá não saiamos. Neste caso, o 
personagem de Linear é ele mesmo o outro, apesar de se achar cartograficamente no lado de cá da fronteira.

A narrativa sonoro/imagética de Corbijn, embora não tenha sido elaborada com pretensões diretamente geográficas, coloca para a geografia possibilidades de (re)pensar os sentidos de orientação e localização no mundo que não reproduzam os mesmos limites de leituras geográficas hegemônicas, da crença em linearidades uniformes em bases físicas imóveis, de paisagens não percebidas em suas profundas superficialidades de diferenças em movimento.

Procuramos, assim, mostrar que o sentido de território está no movimento, no constante ritornelo, que ao territorializar certo fenômeno, tornálo compreensível, estabelece novas linhas de fuga e o mobiliza para outros lugares, indo ao encontro no/do mundo, pois a geografia não está fora ou externa ao homem, como um palco imóvel em que as coisas acontecem sobre.

A geografia é saber em processo, é conhecimento do mundo no ato do encontro, de todos os encontros do homem com os mais diversos fenômenos.

Como colocam Deleuze e Guattari (1997), o personagem de Linear saiu "de casa no fio de uma cançãozinha" e foi ao encontro do mundo, para melhor saber se localizar e se orientar.

Ao territorializar sua geografia, identificou-se como ser em movimento. As sonoridades "que marcam o percurso", ou seja, o ritornelo U2 potencializou novos territórios para o seu ser, jamais fixos, sempre em processo, sem linhas no horizonte, apenas movimento. Neste sentido, não há como voltar para casa, pois o em-casa é o movimento, um constante repetir do devir das diferenças de paisagens em diferenciação.

\section{Referências}

CARVALHO, Márcia. A trilha sonora do cinema: proposta para um ouvir analítico. Revista Caligrama, vol. 3, n ${ }^{\circ}$ 1. São Paulo: ECA, p. 1-15, jan/abr de 2007. Disponível em: www.eca.usp.br/caligrama/n_7/pdf/marcia.pdf. Acessado em 02/04/2011.

DELEUZE, Gilles. A Imagem-Tempo (Cinema II). São Paulo: Brasiliense, 2007. DELEUZE, Gilles. A Imagem-Movimento (Cinema I). Lisboa: Assírio \& Alvim, 2009. 329 p.

DELEUZE, Gilles, GUATTARI, Félix. O que é Filosofia? São Paulo: Ed. 34, 1992, $288 \mathrm{p}$. 
DELEUZE, Gilles, GUATTARI, Félix. Mil Platôs: capitalismo e esquizofrenia - vol. 1. São Paulo: Ed. 34, 1995. 96 p.

DELEUZE, Gilles, GUATTARI, Félix. Mil Platôs: capitalismo e esquizofrenia - vol. 4. São Paulo: Ed. 34, 1997. 170 p.

Cláudio Benito Oliveira Ferraz

Mestre e Doutor em Geografia pela Universidade de São Paulo.

Atualmente é professor da Universidade Estadual Paulista - Campus de Presidente

Prudente.

Rua Roberto Simonsen, 305 - Presidente Prudente (SP) - CEP 19060-900

E-mail: cbenito2@yahoo.com.br

\section{Flaviana Gasparotti Nunes}

Mestre e Doutora em Geografia pela Universidade Estadual Paulista Júlio de Mesquita Filho - Campus de Presidente Prudente. Possui estágio de Pós-Doutorado na Universidade Federal do Rio de Janeiro. Atualmente é professor adjunto da Universidade Federal da Grande Dourados onde coordena o Programa de Pós-Graduação em Geografia.

Rod. Dourados-Itahum, Km 12 - Dourados (MS) - CEP 79804-970

E-mail: flaviananunes@ufgd.edu.br

Recebido para publicação em novembro de 2013

Aprovado para publicação em dezembro de 2013 